\title{
Effect of spirometry on COPD management in primary care: where are the studies that we really need?
}

\section{To the Editors:}

In the November 2006 issue of the European Respiratory Journal, WALKER et al. [1] reported on the effects of the use of spirometry to diagnose chronic obstructive pulmonary disease (COPD) in primary care and the resulting benefits for patient management. In patients referred to an open-access spirometry service by their general practitioner, the diagnosis and current management of the patients was assessed before and after spirometry testing. WALKER et al. [1] observed a change of diagnosis after spirometry in: $71 \%$ of patients who had no respiratory diagnosis at the time of the referral; $48 \%$ of patients who had previously been diagnosed with asthma; and 23\% of patients with a COPD diagnosis. Drug prescription changed in $49 \%$ of the COPD patients, with a marked increase in the prescription of long-acting bronchodilators and inhaled corticosteroids. Last but not least, the authors reported that smoking cessation advice was given to $76 \%$ of the COPD patients who were current smokers.

Despite the increasing accessibility, spirometry is still underused in primary care for several reasons [2]. In the study by WALKER et al. [1], the use of spirometry had a confirmative role for COPD patients and an even greater role in patients with asthma and in patients with respiratory complaints without a diagnosis. The observed change of diagnosis and effects on pharmacological and nonpharmacological management after spirometry are not surprising, given the results from other recent studies (personal communication, B.P. Yawn, Dept of Research, Olmsted Medical Center, Rochester, MN, USA, and [3-5]). Although we fully agree with these authors that the effect of spirometry on COPD management and subsequent adherence with guideline recommendations cannot formally be assessed with retrospective or nonrandomised studies, we also argue that these are not the most relevant issues to focus our research efforts on. After all, could we really expect that the addition of the information that is required to demonstrate airways obstruction but that, for whatever reason, was not available before, would change diagnosis and management in patients with suspected obstructive airways disease? More generally, if a (primary-care) physician does not have access to an essential diagnostic tool like spirometry, it should hardly come as a surprise that he/she will able to provide better care once this tool is made accessible, especially as it was already shown over two decades ago by SPANN [6] that spirometry is likely to impact on the primary-care management of COPD.

What, then, should be the next steps that investigators in this field of research should take? If we are still not convinced about the fact that proper diagnostics requires proper tools, we need robust randomised controlled trials with an adequate comparator group to establish the true value of spirometry above the physician's reassessment of diagnosis and management without the additional input of spirometry test results. In our view, however, the following research questions would be more worthwhile as the focus of our research activities. 1) What is the additional value of spirometry on top of history-taking and clinical examination in subjects who consult their primary-care physician with signs or symptoms that may point to an underlying obstructive airways disease? (Or, in other words, what are the positive and negative predicted values of spirometry in these subjects?) 2) What is the effect of spirometry on a primary-care physician's certainty about a diagnosis, and what are the consequences in terms of ordering of additional diagnostic tests and referrals to specialists? 3) How can we support primary-care physicians with their interpretation of spirometry tests, which is often not as adequate as secondary-care respiratory specialists would like to see $[7,8]$ ? Only with well-designed studies that address these questions can we really move the research on the value of spirometry for primary-care physicians and their patients forward.

\section{P.J.P. Poels, D.P.A. Schellekens and T.R. Schermer}

Dept of General Practice, Radboud University Nijmegen Medical Centre, Nijmegen, The Netherlands.

\section{STATEMENT OF INTEREST}

None declared.

\section{REFERENCES}

1 Walker PP, Mitchell P, Diamantea F, Warburton CI, Davies L. Effect of primary-care spirometry on the diagnosis and management of COPD. Eur Respir J 2006; 28: 945-952.

2 Poels PJ, Schermer TR, van Weel C, Calverley PM. Spirometry in chronic obstructive pulmonary disease. $B M J$ 2006; 333: 870-871.

3 Dales RE, Vandemheen KL, Clinch J, Aaron SD. Spirometry in the primary care setting: influence on clinical diagnosis and management of airflow obstruction. Chest 2005; 128: 2443-2447.

4 Bolton CE, Ionescu AA, Edwards PH, Faulkner TA, Edwards SM, Shale DJ. Attaining a correct diagnosis of COPD in general practice. Respir Med 2005; 99: 493-500.

5 Chavannes N, Schermer T, Akkermans R, et al. Impact of spirometry on GPs' diagnostic differentiation and decisionmaking. Respir Med 2004; 98: 1124-1130.

6 Spann SJ. Impact of spirometry on the management of chronic obstructive airway disease. J Fam Pract 1983; 16: 271-275.

7 Raghunath AS, Innes A, Norfolk L, et al. Difficulties in the interpretation of lung function tests in the diagnosis of asthma and chronic obstructive pulmonary disease. J Asthma 2006; 43: 657-660.

8 Tinkelman DG, Price DB, Nordyke RJ, Halbert RJ. Misdiagnosis of COPD and asthma in primary care patients 40 years of age and over. J Asthma 2006; 43: 75-80.

DOI: $10.1183 / 09031936.00154406$ 